\title{
Exploring assistive technology as a potential beneficial intervention tool for people with Alzheimer's disease - a systematic review
}

This article was published in the following Dove Press journal:

Neuropsychiatric Disease and Treatment

\author{
Blanka Klimova' \\ Martin Valis ${ }^{2}$ \\ Kamil Kuca ${ }^{3}$ \\ 'Department of Applied Linguistics, \\ Faculty of Informatics and \\ Management, University of Hradec \\ Kralove, Hradec Kralove, Czech \\ Republic; ${ }^{2}$ Department of Neurology, \\ University Hospital Hradec Kralove, \\ Hradec Kralove, Czech Republic; \\ ${ }^{3}$ Centre for Basic and Applied \\ Research, University Hospital \\ Hradec Kralove, Hradec Kralove, \\ Czech Republic
}

\begin{abstract}
Nowadays, due to the increase in the number of aging population groups, there is also a growth of aging diseases such as Alzheimer's disease (AD), which is a progressive brain disorder that eventually results in death. At the moment, it cannot be cured, only its symptoms can be alleviated both by using pharmacological and non-pharmacological approaches in order to maintain and in some cases even enhance quality of life of people living with AD, as well as their caregivers. One of such non-pharmacological approaches is the use of assistive technology (AT), which can contribute to the improvement and maintenance of the quality of life of both patients and their caregivers. The purpose of this study was to explore what types of AT are mostly used by patients with AD and how these devices can help their caregivers. This was done by conducting a literature review of available sources found in the Web of Science, Scopus, and PubMed. The findings, apart from one study, reveal that AT may have the potential to maintain the quality of life of people with $\mathrm{AD}$, especially in the early stages of the disease, as well as to mitigate the mental and physical burden of their caregivers. The most common types of AT for patients with AD are devices of daily living and safety devices. The less frequent are still telecare devices and devices to support engagement, social participation, and leisure. Future research should focus on the effectiveness of AT on the improvement of patients' symptoms, as well as on the development and use of AT for social interactions, which can be used in patients with $\mathrm{AD}$ of different degree of severity and have a positive impact on their behavioral and psychological symptoms.
\end{abstract}

Keywords: assistive technology, Alzheimer's disease, patients, caregivers, benefits

\section{Introduction}

Currently, there are about 44 million people in the world living with Alzheimer's disease $(\mathrm{AD})$. Due to the demographic trends toward the aging of population, this number will be rising. In fact, by 2050 , this number will triple. ${ }^{1}$ AD is a progressive neurological disorder, which first affects cognitive skills and eventually results in the inability to do the tasks of daily life. It is one of the most common forms of dementia. In the course of $\mathrm{AD}$, many neurons stop functioning, lose connections with other neurons, and die. ${ }^{2} \mathrm{AD}$ damages neurons and their connections in parts of the brain involved in memory. It later affects areas in the cerebral cortex responsible for language, reasoning, and social behavior such apathy, depression, delusions, hallucinations, aggression, irrelevant sexual behavior, or sleeping problems. ${ }^{3}$ The symptoms of AD gradually worsen and the patients will not be able to take care of themselves alone. Therefore, they begin to be severely dependent of someone's help, which is usually provided by a family member. For example, in 2016 there were 15.9 million family caregivers who
Correspondence: Kamil Kuca Centre for Basic and Applied Research, University Hospital Hradec Kralove, Sokolska 58I, Hradec Kralove, 500 05, Czech Republic

Tel +420603289166

Fax +420495835200

Email kamil.kuca@fnhk.cz (c) (1) (5) 2018 Klimova et al. This work is published and licensed by Dove Medical Press limited. The full terms of this license are available at https://www.dovepress.com/terms.php cc) and incorporate the Creative Commons Attribution - Non Commercial (unported, v3.0) License (http://(creativecommons.org/licenses/by-nc/3.0/). By accessing the work you hereby accept the Terms. Non-commercial uses of the work are permitted without any further permission from Dove Medical Press Limited, provided the work is properly attributed. For permission for commercial use of this work, please see paragraphs 4.2 and 5 of our Terms (https://www.dovepress.com/terms.php). 
provided an estimated 18.2 billion hours of care. ${ }^{4}$ In most of the cases, these caregivers have to give up their jobs; they lose their private and social life. In addition, their economic situation decreases as well. ${ }^{5}$ Thus, AD represents mental and economic burden not only for patients themselves but also for their caregivers. The global cost of AD and dementia is estimated to be $\$ 605$ billion, which is equivalent to $1 \%$ of the entire world's gross domestic product. ${ }^{4}$

At present, there is no cure for AD. There have been only four clinically approved drugs (ie, donepezil, galantamine, memantine, and rivastigmine). They can help patients to delay the process of the disease for some time, which is quite expensive and has negative side effects, and they do not help patients to improve their physical or social conditions. ${ }^{6,7}$ Therefore, people also look for alternative, non-pharmacological approaches to the alleviation of AD. One of such approaches might be assistive technology (AT), which has the potential to improve and maintain the quality of life of both patients and their caregivers. ${ }^{8}$ It helps patients with AD to increase their safety, confidence, independence, as well as to reduce their behavioral and psychological symptoms of $\mathrm{AD}$ and maintain cognitive functioning. In addition, it can help caregivers to be more flexible, attempt to maintain patients' cognition, improve their mood and social functioning, and reduce the use of services. ${ }^{9}$

AT is usually defined as "any item, piece of equipment, or product system, whether acquired commercially, modified, or customized, that is used to increase, maintain, or improve functional capabilities of individuals with disabilities." 10 It can be divided according to its purpose into supportive technologies, which help people to complete tasks; responsive technologies, which can help to control stress and raise alarms; and preventive technologies, which can help to prevent harm and raise alarms. ${ }^{11}$

The AT can be a very simple device, such as a walking stick, a walking frame, or calendar clocks. It can be a more sophisticated device such as automatic lighting and telecare, such as movement, flood, gas, smoke, or fall detectors that automatically send a signal via a base unit connected to a telephone line to a caregiver, community alarm, or monitoring service, and which can call for assistance when it is needed. ${ }^{11}$

Alzheimer's Society ${ }^{11}$ distinguishes the following four types of AT on the basis of their purpose:

- Devices of daily living.

- Safety devices.

- Telecare devices.

- Devices to support engagement, social participation, and leisure.

\section{Devices of daily living}

These technologies include the devices, which help people with $\mathrm{AD}$ with their memory, orientation, and communication difficulties. These are mainly prospective memory aids including devices focused on time orientation, keeping appointments, or reminding people of attending social activities. ${ }^{12}$ Furthermore, calendar clocks help them to be aware of the relevant date and time, while the orientation devices such as the locaters help them to find the way or things. The adapted telephones, on the contrary, help them with communication. ${ }^{11}$

\section{Safety devices}

Safety devices can enable people to live independently, as well as reduce worries of their loved ones about them. These technologies comprise different devices such as automatic lights, automated shut-off devices that can stop the gas supply if the gas has been left on, water isolation devices that control water taps and prevents flooding, or fall sensors that can register if a person has fallen. Therefore, AT is sometimes referred to as ambient assisted living (AAL) since its aim is also to support people to live independently. In addition, the AAL technologies can collect characteristics/data about patients with $\mathrm{AD}$ through a non-intrusive wireless sensor system, whose data can provide valuable information about these patients in real-time. ${ }^{13}$

Moreover, these safety devices also include tracking devices or location-monitoring services, which enable to find the persons if they get lost and at the same time enable the persons with AD to call for help if they are disoriented and cannot find the way on their own. ${ }^{14}$

\section{Telecare devices}

Telecare usually refers to a system or devices that remotely monitor people living in their own home, enabling them to access support or response services when necessary. Various pieces of technology are connected via a telephone line or over the Internet. Telecare systems can include community alarms, sensors and movement detectors, video conferencing, or assistive robots. ${ }^{15}$

\section{Devices to support engagement, social participation, and leisure}

Apart from living independently and safe, it is important for people with $\mathrm{AD}$ to stay in touch with their family, friends, and peers since such a social contact has a positive impact on their cognition, mood, and well-being. ${ }^{16}$ And with the boom of mobile technologies, it is quite easy. Patients can play 
games, get involved into computer brain training programs or just chat with their loved ones. ${ }^{11}$

All these devices described above are targeted at the enhancement of the quality of life of people with $\mathrm{AD}$, as well as their caregivers. However, each of the patients is individual and may have different needs. Therefore, it is important to carefully assess their needs and consequently, tailor this AT accordingly. ${ }^{17}$ As Pino et a ${ }^{18}$ claim, development of new assistive technologies to support patients with $\mathrm{AD}$ and their caregivers requires the enduser involvement throughout all the development lifecycle.

The purpose of this study was to explore what types of AT are mostly used by patients with $\mathrm{AD}$ and how these devices can help them and their caregivers. The authors thus set three main research questions, which are as follows:

1. What types of AT are used by patients with AD?

2. What are the main benefits of AT both for patients and their caregivers?

3. Do the findings of the detected studies evidence any AT effectiveness on the maintenance or even improvement of patients' symptoms, and thus their quality of life?

\section{Methods}

The authors conducted a literature review of available sources found in the Web of Science, Scopus, and PubMed. The methodology of this study was based on Moher et al. ${ }^{19}$ The search keywords were as follows: assistive technology AND Alzheimer's disease, assistive technology AND dementia, devices of daily living AND Alzheimer's disease, safety devices AND Alzheimer's disease, telecare devices AND Alzheimer's disease, leisure devices AND Alzheimer's disease, social devices AND Alzheimer's disease, engagement devices AND Alzheimer's disease, devices of daily living AND dementia, safety devices AND dementia, telecare devices AND dementia, leisure devices AND dementia, social devices AND dementia, engagement devices AND dementia. The search was limited only by the end of the study, that is, July 2018.

From the database/journal/web page searches, 687 titles/ abstracts were retrieved. The title and abstract of some identified studies were checked for relevance. Subsequently, the search was performed again and focused on the occurrence of at least one keyword in the title or abstract, thus significantly narrowing the selection. It provided the authors with a relevant entry-level file base. Altogether 73 studies were found. After removing duplicates and titles/abstracts unrelated to the research topic, 37 peer-reviewed, studies written in English were identified. After the full-text analysis, 10 studies were eventually included in final analysis (Figure 1).

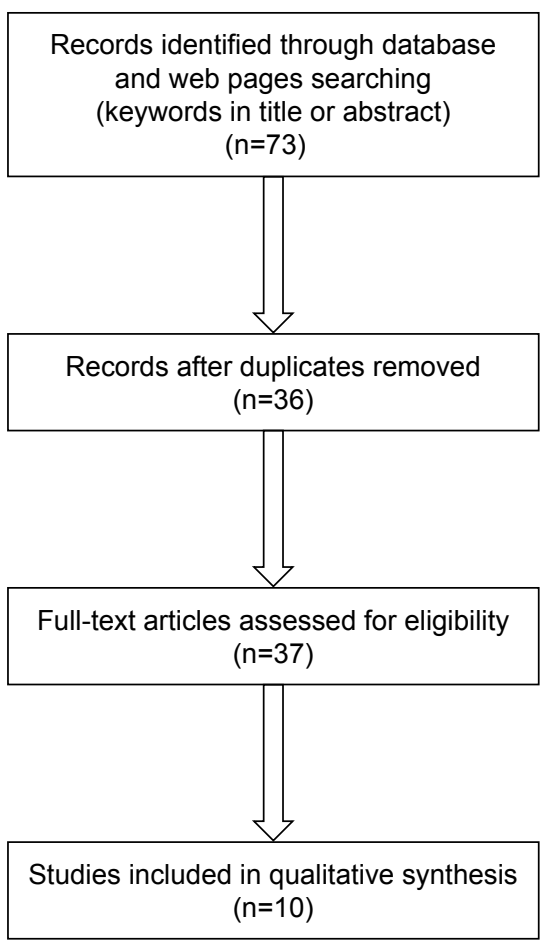

Figure I Selection procedure.

A study was included if it was a randomized controlled study, an experimental study or a case study; it dealt with the research topic, ie, AT as an intervention tool for people with $\mathrm{AD}$, and possibly their caregivers; was limited by the end of July 2018; and if it was written in English. Thus, descriptive or review studies on the research topic were excluded for the analysis. Furthermore, the studies focusing on dementia in general, ${ }^{16,20-22}$ exclusively only on caregivers, ${ }^{23}$ or containing no intervention ${ }^{24}$ were also excluded. In this way, this review differs from the review by Meiland et $\mathrm{al}^{9}$ who did not set any limitations as far as the topic on the use of AT and patients with dementia is concerned. In their study, they analyzed mainly reviews. Nevertheless, remaining suitable studies were then used in other parts of this manuscript (ie, "Introduction" or "Discussion of the findings" section) in order to describe the topic and compare the findings.

\section{Findings}

Altogether ten studies ${ }^{25-34}$ were detected. Nine of them were experimental studies, ${ }^{26-34}$ and one study ${ }^{24}$ was a randomized controlled trial. All patients suffered from $\mathrm{AD}$, and this was measured with the Mini-Mental State Examination test. This test is used worldwide to detect cognitive function, dementia, and $\mathrm{AD}$. The methodology for measuring the outcomes of the use of $\mathrm{AT}$ in patients with $\mathrm{AD}$ differed across the selected studies. The researchers used both quantitative 
and qualitative methods, such as questionnaires, interviews, instrumental activities of daily living, recordings, and in some cases, statistical processing. The subject samples included between 1 and 48 patients with AD, including caregivers. These relatively small numbers of subjects are due to the inclusion of experimental/case studies whose samples are usually limited by the nature of the study. The intervention period ranged from 1 to 12 months. The AT included different devices, which were especially aimed at patients' safety and security ${ }^{27,28}$ and activities of daily living. ${ }^{25,26,32,33}$ We found only two studies focused on the devices to support leisure engagement ${ }^{30}$ and cognitive training, ${ }^{34}$ and one study ${ }^{29}$ on telecare devices. The key limitation of the studies was the varying levels of $\mathrm{AD}$ among patients. The description of the analyzed studies and their findings are summarized in alphabetical order of their first author in Table 1.

\section{Discussion of the findings}

Although there was only one $\mathrm{RCT},{ }^{25}$ which revealed no improvement as far as behavioral symptoms, functional status, or QoL of hearing impaired AD patients and their caregivers after 6 months of hearing aid use are concerned, findings from other experimental studies indicate that AT may generate a positive effect on patients' and their caregivers' quality of life in several ways. In the early stages of AD, AT may especially promote their independent living, ${ }^{26-29,31-33}$ which patients prefer ${ }^{35,36}$ and which can also delay the costly institutionalization. ${ }^{37}$ In these early stages of $\mathrm{AD}$, patients can also get engaged in leisure activities supported by AT, such as listening to music, picture viewing, or solving puzzles, which may have a positive effect not only on their mood but also on cognitive functions. ${ }^{16,30,34}$ Furthermore, AT may help to maintain patients' safety and security, which thus means less stress and confidence not only for them but also less worries and greater relaxation for their caregivers. ${ }^{27-29}$ In fact, nearly $45 \%$ of patients with AD suffer from depressive symptoms and 10\%-45\% from anxiety. ${ }^{25,38}$ As Franco et al ${ }^{29}$ state, AT is able to detect loss of independence. It can, for instance, reveal the details of activity that people stop doing, for example, vacuuming or ironing. In addition, the use of robots, which can assist people with $\mathrm{AD}$ by providing them with stepwise prompts seems to be of more interest and motivation for people with mild-to-moderate AD. ${ }^{33}$ At present, there are also animallike robots that engage patients with dementia and $A D$ in social interactions and help them to reduce their behavioral and psychological symptoms. ${ }^{38,39}$
The results from the selected studies ${ }^{27,29,32,33}$ of this review confirm the findings of other studies ${ }^{18,37,40}$ that it is desirable for the developers of AT to focus on the end-users, that is, the patients themselves, as well as on their caregivers, who should also be trained in their use. Moreover, the use of AT in the daily life of caregivers can help them to understand the disease process and manage situations in a way that is beneficial for both the parties. ${ }^{35}$ The doctors should also be approached in order to judge the appropriateness of the device to patients' diagnosis and their needs. The developers should pay particular attention to the size of AT device, its weight, and visibility to reduce stigmatization, ${ }^{21}$ as well as making it user-friendly to its users. ${ }^{28}$ For instance, Czarnuch et $\mathrm{al}^{41}$ developed a set of models that can predict the likelihood that patients with dementia, and $\mathrm{AD}$, will require assistance during 20 activities of daily living without direct evaluation of their actual capabilities. These models are shaped by the following 13 factors: caregiver relation, age, marital status, place of residence, language, housing type, proximity to caregiver, use of professional service, informal primary caregiver, diagnosis of AD, diagnosis of dementia, time since diagnosis, and level of dependence on caregiver. Knowledge of task independence can then inform the development of AT for people with AD and improve their applicability and acceptance.

Furthermore, there are also ethical concerns about the use of AT devices; some technologies may intrude patients' rights, privacy, and freedom such as a global positioning system used by patients with AD. Overall, there are two main ethical dilemmas: privacy and respect for autonomy vs safety and minimizing risks, and obtaining informed consent from persons with dementia due to their possible difficulties understanding the complexity of technology. ${ }^{9}$

Therefore, patients with AD as well as their caregivers should be involved in the decision making and their consent should be sought. ${ }^{42}$ In addition, Bennett et $\mathrm{al}^{43}$ suggest establishing an approach that would evaluate innovative technologies with respect to human rights set in the United Nations Convention on the Rights of Persons with Disabilities.

The limitations of this review are a lack of available studies on the research topic, based on the inclusion and exclusion criteria set by the authors. Furthermore, the validity of the findings might also be influenced by varying levels of AD that were studied, different types of AT devices, short intervention periods, a lack of follow-up periods (in most of the studies), and a lack of other reliable data, for example, effect sizes. $^{44}$ 


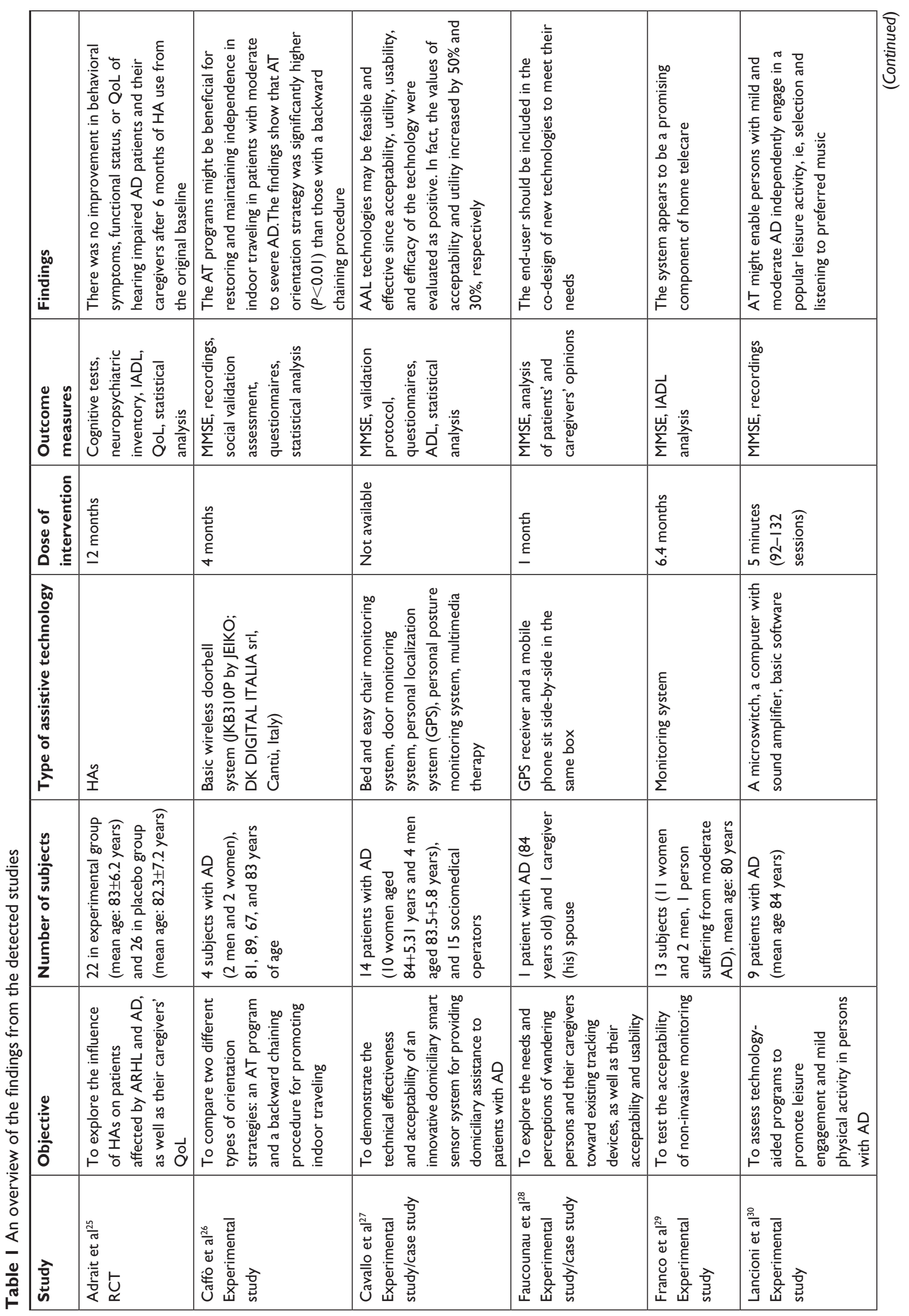




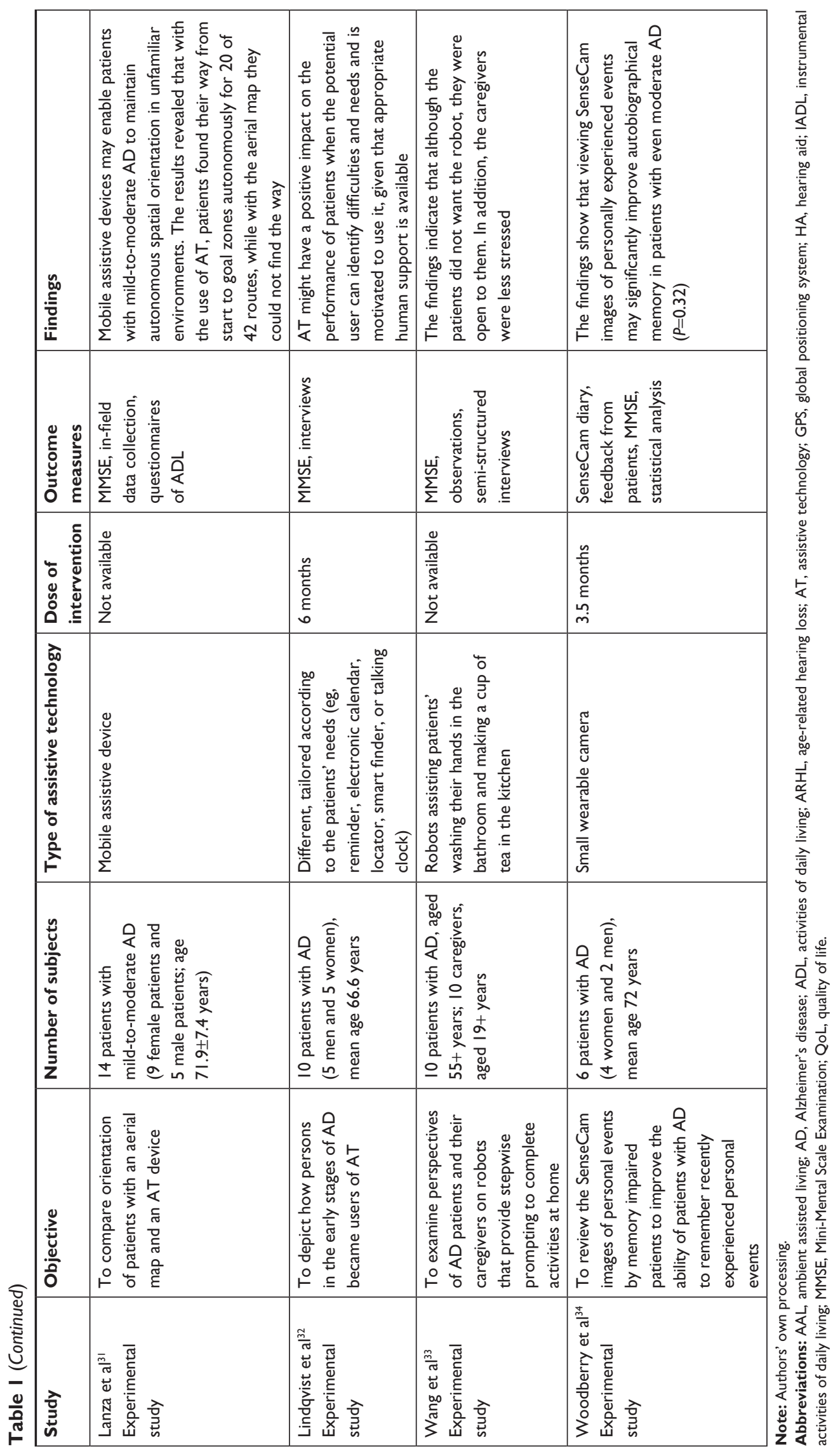




\section{Conclusion}

Thus, based on the findings from this review, the research questions can be answered. The most common types of AT for patients with $\mathrm{AD}$ are devices of daily living and safety devices. The less frequent are still telecare devices and devices to support engagement, social participation, and leisure. The main benefits for patients using them include the feeling of being independent and the feeling of having confidence of being able to execute the activity of daily living, and thus, maintaining the quality of life, as well as reducing adverse behavioral and psychological symptoms. The caregivers then benefit from gaining more independence and mitigating their mental and physical burden. In fact, only two studies ${ }^{26,34}$ evidenced (through effect sizes) the effectiveness of AT on the improvement of patients' symptoms. Therefore, future research should focus on this issue, as well as on the development and use of AT for social interactions, which can be used in patients with $\mathrm{AD}$ of different degree of severity and have a positive impact on their behavioral and psychological symptoms.

\section{Acknowledgments}

The paper was supported by the project SPEV 2104/2018 run at the Faculty of Informatics and Management of the University of Hradec Kralove, Czech Republic, and by the research project MH CZ - DRO (UHHK 00179906) and by PROGRES Q40 run at the Medical Faculty of Charles University.

\section{Disclosure}

The authors report no conflicts of interest in this work.

\section{References}

1. Langa KM. Is the risk of Alzheimer's disease and dementia declining? Alzheimers Res Ther. 2015;7:1-4.

2. Alzheimer's Society. Alzheimer's disease. Available from: https://www. alzheimers.org.uk/info/20007/types_of_dementia/2/alzheimers_disease. Accessed March 12, 2018.

3. Klimova B, Kuca K. Alzheimer's disease and Chinese medicine as a useful alternative intervention tool: a mini-review. Curr Alzheimer Res. 2017;14(6):680-685.

4. 2017 Alzheimer's Statistics. Available from: https://www.alzheimers. net/resources/alzheimers-statistics/. Accessed March 12, 2018.

5. Maresova P, Klimova B, Novotny M, Kuca K. Alzheimer's and Parkinson's diseases: expected economic impact on Europe-a call for a uniform european strategy. J Alzheimers Dis. 2016; 54(3):1123-1133.

6. Klimova B, Maresova P, Valis M, Hort J, Kuca K. Alzheimer's disease and language impairments: social intervention and medical treatment. Clin Interv Aging. 2015;10:1401-1408.

7. Klimova B, Valis M, Kuca K. Dancing as an intervention tool for people with dementia: a mini-review dancing and dementia. Curr Alzheimer Res. 2017;14(12):1264-1269.
8. Daly Lynn J, Rondón-Sulbarán J, Quinn E, Ryan A, McCormack B, Martin S. A systematic review of electronic assistive technology within supporting living environments for people with dementia. Dementia (London). 2017;1:1471301217733649.

9. Meiland F, Innes A, Mountain G, et al. Technologies to support community-dwelling persons with dementia: a position paper on issues regarding development, usability, effectiveness and cost-effectiveness, deployment, and ethics. JMIR Rehabil Assist Technol. 2017;4(1):e1.

10. Summary of assistive technology act of 1998, as amended 2004, Public Law 108-364. Available from: https://www.ataporg.org/ATActSummary. Accessed November 8, 2018.

11. Alzheimer's Society. Alzheimer's Society's view on assistive technology; 2013. Available from: https://www.alzheimers.org. uk/info/20091/what_we_think/85/assistive_technology. Accessed March 12, 2018

12. King AC, Dwan C. Electronic memory aids for people with dementia experiencing prospective memory loss: a review of empirical studies. Dementia. 2017;1:147130121773518.

13. Stucki RA, Urwyler P, Rampa L, Müri R, Mosimann UP, Nef T. A webbased non-intrusive ambient system to measure and classify activities of daily living. $J$ Med Internet Res. 2014;16(7):e175.

14. Mckinstry B, Sheikh A. The use of global positioning systems in promoting safer walking for people with dementia. $J$ Telemed Telecare. 2013;19(5):288-292.

15. Lorenz K, Freddolino PP, Comas-Herrera A, Knapp M, Damant J. Technology-based tools and services for people with dementia and carers: Mapping technology onto the dementia care pathway. Dementia. 2017;1:147130121769161.

16. Vahia IV, Kamat R, Vang C, et al. Use of tablet devices in the management of agitation among inpatients with dementia: an open-label study. Am J Geriatr Psychiatry. 2017;25(8):860-864.

17. Ienca M, Fabrice J, Elger B, et al. Intelligent assistive technology for Alzheimer's disease and other dementias: a systematic review. J Alzheimers Dis. 2017;56(4):1301-1340.

18. Pino M, Boulay M, Legouverneur G, Yh W, Cristancho-Lacroix V, Rigaud AS. Assistive technologies for older adults with Alzheimer's disease: the Lusage user-lab experience. Alzheimers Dement. 2011;7(4): S442.

19. Moher D, Liberati A, Tetzlaff J, Altman DG; PRISMA Group. Preferred reporting items for systematic reviews and meta-analyses: the PRISMA statement. PLoS Med. 2009;6(7):e1000097.

20. Buettner LL, Fitzsimmons S. AD-venture program: therapeutic biking for the treatment of depression in long-term care residents with dementia. Am J Alzheimers Dis Other Demen. 2002;17(2):121-127.

21. Robinson L, Brittain K, Lindsay S, Jackson D, Olivier P. Keeping In Touch Everyday (KITE) project: developing assistive technologies with people with dementia and their carers to promote independence. Int Psychogeriatr. 2009;21(3):494-502.

22. Toots A, Littbrand H, Holmberg H, et al. Walking aids moderate exercise effects on gait speed in people with dementia: a randomized controlled trial. J Am Med Dir Assoc. 2017;18(3):227-233.

23. Farran CJ, Loukissa D, Perraud S, Paun O. Alzheimer's disease caregiving information and skills. Part II: family caregiver issues and concerns. Res Nurs Health. 2004;27(1):40-51.

24. Hall A, Wilson CB, Stanmore E, Todd C. Implementing monitoring technologies in care homes for people with dementia: a qualitative exploration using Normalization Process Theory. Int J Nurs Stud. 2017; 72:60-70

25. Adrait A, Perrot X, Nguyen MF, et al. Do hearing aids influence behavioral and psychological symptoms of dementia and quality of life in hearing impaired Alzheimer's disease patients and their caregivers? J Alzheimers Dis. 2017;58(1):109-121.

26. Caffò AO, Hoogeveen F, Groenendaal M, et al. Comparing two different orientation strategies for promoting indoor traveling in people with Alzheimer's disease. Res Dev Disabil. 2014;35(2):572-580. 
27. Cavallo F, Aquilano M, Arvati M. An ambient assisted living approach in designing domiciliary services combined with innovative technologies for patients With Alzheimer's disease. Am J Alzheimers Dis Other Demen. 2015;30(1):69-77.

28. Faucounau V, Riguet M, Orvoen G, et al. Electronic tracking system and wandering in Alzheimer's disease: a case study. Ann Phys Rehabil Med. 2009;52(7-8):579-587.

29. Franco GC, Gallay F, Berenguer M, Mourrain C, Couturier P. Non-invasive monitoring of the activities of daily living of elderly people at home - a pilot study of the usage of domestic appliances. J Telemed Telecare. 2008;14(5):231-235.

30. Lancioni GE, Singh NN, O'Reilly MF, et al. Persons with Alzheimer's disease engage in leisure and mild physical activity with the support of technology-aided programs. Res Dev Disabil. 2015;37:55-63.

31. Lanza C, Knörzer O, Weber M, Riepe MW. Autonomous spatial orientation in patients with mild to moderate Alzheimer's disease by using mobile assistive devices: a pilot study. J Alzheimers Dis. 2014;42(3): 879-884.

32. Lindqvist E, Nygård L, Borell L. Significant junctures on the way towards becoming a user of assistive technology in Alzheimer's disease. Scand J Occup Ther. 2013;20(5):386-396.

33. Wang RH, Sudhama A, Begum M, Huq R, Mihailidis A. Robots to assist daily activities: views of older adults with Alzheimer's disease and their caregivers. Int Psychogeriatr. 2017;29(1):67-79.

34. Woodberry E, Browne G, Hodges S, Watson P, Kapur N, Woodberry K. The use of a wearable camera improves autobiographical memory in patients with Alzheimer's disease. Memory. 2015;23(3):340-349.

35. Evans J, Brown M, Coughlan T, Lawson G, Craven MP. Human-computer interaction: interaction technologies. 17th International Conference, HCI International 2015, Los Angeles, USA. In: Kurosu M, editor. Lecture Notes in Computer Science. New York: Springer International Publishing; 2015.
36. Martínez-Alcalá CI, Pliego-Pastrana P, Rosales-Lagarde A, LopezNoguerola JS, Molina-Trinidad EM. Information and communication technologies in the care of the elderly: Systematic review of applications aimed at patients with dementia and caregivers. JMIR Rehabil Assist Technol. 2016;3(1):e6.

37. O'Keeffe J. The use of assistive technology to reduce caregiver burden; 2017. Available from: https://aspe.hhs.gov/system/files/pdf/257971/ AsstTech.pdf. Accessed March 12, 2018.

38. Moyle W, Jones CJ, Murfield JE, et al. Use of a robotic seal as a therapeutic tool to improve dementia symptoms: a cluster-randomized controlled trial. J Am Med Dir Assoc. 2017;18(9):766-773.

39. Jøranson N, Pedersen I, Rokstad AM, Ihlebæk C. Effects on symptoms of agitation and depression in persons with dementia participating in robot-assisted activity: a cluster-randomized controlled trial. J Am Med Dir Assoc. 2015;16(10):867-873.

40. Kenigsberg PA, Aquino JP, Bérard A, et al. Dementia beyond 2025: Knowledge and uncertainties. Dementia. 2016;15(1):6-21.

41. Czarnuch S, Ricciardelli R, Mihailidis A. Predicting the role of assistive technologies in the lives of people with dementia using objective care recipient factors. BMC Geriatr. 2016;16:143.

42. Landau R, Werner S. Ethical aspects of using GPS for tracking people with dementia: recommendations for practice. Int Psychogeriatr. 2012; 24(3):358-366.

43. Bennett B, Mcdonald F, Beattie E, et al. Assistive technologies for people with dementia: ethical considerations. Bull World Health Organ. 2017;95(11):749-755.

44. Melby-Lervåg M, Hulme C. Is working memory training effective? A meta-analytic review. Dev Psychol. 2013;49(2):270-291.
Neuropsychiatric Disease and Treatment

\section{Publish your work in this journal}

Neuropsychiatric Disease and Treatment is an international, peerreviewed journal of clinical therapeutics and pharmacology focusing on concise rapid reporting of clinical or pre-clinical studies on a range of neuropsychiatric and neurological disorders. This journal is indexed on PubMed Central, the 'PsycINFO' database and CAS,

\section{Dovepress}

and is the official journal of The International Neuropsychiatric Association (INA). The manuscript management system is completely online and includes a very quick and fair peer-review system, which is all easy to use. Visit http://www.dovepress.com/testimonials.php to read real quotes from published authors. 